ISSN electrónico: 2172-9077

DOI: https://doi.org/10.14201/fjc201919251253

\title{
LAS DIFERENTES CARAS DEL ARTE CINEMATOGRÁFICO EN MANUEL GuTIÉRREZ AragÓN
}

\section{The Different Faces of Cinematographic Art in Manuel Gutiérrez Aragón}

\author{
Dr. Miguel Ángel PÉREZ-GÓMEZ \\ Profesor sustituto interino \\ Universidad de Sevilla. España. \\ E-mail: mperez21@us.es \\ (iD) https://orcid.org/0000-0002-7315-1809
}

Fecha de recepción de la reseña: 05/09/2019

Fecha de aceptación definitiva: 24/10/2019

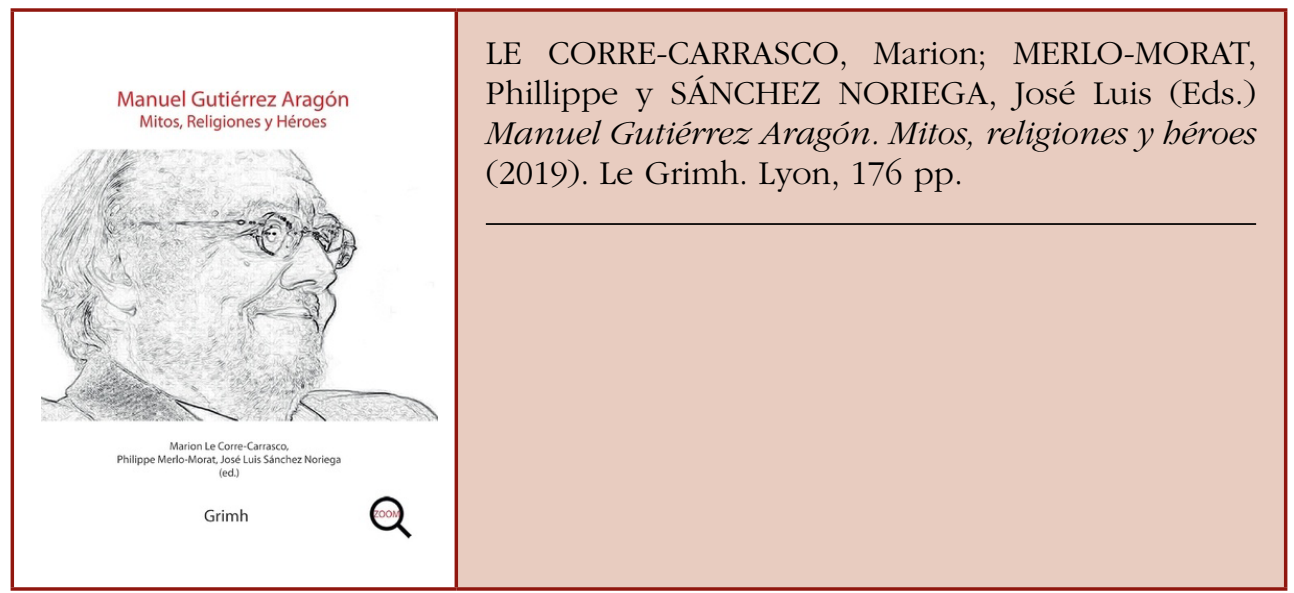

Con el tiempo, el viaje que la academia debe de realizar a la hora de revisitar la filmografía de un director de cine consagrado no pasa solo por la idea de ponerlo en el mapa en función del contexto sociopolítico en el que un creador determinado desarrolla su carrera; Si no que con el tiempo empiezan a aparecer una serie de grietas que permiten volcar una nueva mirada sobre las obras en cuestión. Philippe Merlo-Morat, Marion Le Corre-Carrasco y José Luis Sánchez Noriega llevan a cabo la labor de coordinación del libro coral titulado Manuel Gutiérrez Aragón. Mitos, religiones y héroes en el que se plantean nuevas brechas en la investigación de la obra del realizador cántabro. 
Este volumen tiene como punto de partida abrirnos a un cine español que define a la perfección la sociedad de finales del siglo XX y que se diferencia del actual por no rendirse tanto a las fórmulas narrativas estadounidense, ni a una homogenización estética actualmente internacionalizada. Un cine que se rinde más a la cultura propia que a la ajena. Cada uno de los capítulos, que repasaremos con un poco más de atención, resalta la ligazón entre la creación y religión, mediante lo sagrado, la transgresión, las creencias y la construcción de la identidad.

El volumen se inicia con un prólogo escrito por el mismo Gutiérrez Aragón a través del cual nos da unas pistas sobre de dónde proviene su imaginario personal y la manera en que decide narrar visualmente la historia. Relatos juveniles clásicos, familia, religión, así como una omnipresencia de la historia contemporánea de España, constituyen algunos de sus elementos principales. Tras el prólogo le sigue el capítulo que Bénédicte Breémard dedica a analizar el film Visionarios (2001) desde el punto de vista de los cuerpos enfrentados y la relación de estos con la religión o, más concretamente, la fe. La autora apunta la relación entre cuerpo e imagen cinematográfica en un caso de niños que han sido testigos de una aparición mariana.

Óscar Curieses nos adentra en la vertiente literaria de Gutiérrez Aragón tras haber dejado la labor de realizador. En primer lugar, habla de A los actores (2015), esta obra versa, de manera cronológica, sobre la labor de director y su relación con los interpretes de sus películas partiendo de la importancia del rostro de los actores en la historia del cine. Por otro lado, el autor del capítulo analiza lo cinematográfico en las dos novelas del realizador cántabro: Cuando el frío llegue al corazón (2013) y El ojo del cielo (2018). EL siguiente capítulo, escrito por Agustín Gómez Gómez, examina el impacto de la naturaleza como escenario en Habla mudita (1973), El corazón del bosque (1978) y La vida que te espera (2004). La naturaleza y lo rural se construyen como un elemento que se enfrenta a la cultura. La forma de interactuar de los personajes con el escenario determina la función de este último, mientras que para los urbanitas se estructura como hostil para la gente del campo es una relación más compleja que va desde el respeto a la rutina del día a día.

En el texto de Marion Le Corre-Carrasco se profundiza, a través de un análisis de Semana Santa (1992), en la idea de la enseñanza de la cultura religiosa a través de un discurso híbrido, a pesar de que este documental busca más navegar entre las sensaciones y emociones de la Semana Santa sevillana como un epítome en el que se compila todo aquella que hace de este evento la insignia de la semana santa española. Para la autora el aprendizaje se realiza a través de los elementos mostrados en el film y el planteamiento no narrativo de este. Emmanuel Marigno estudia en la adaptación de la obra de Cervantes, El Quijote (1992), como la religión y el antropocentrismo son utilizados en esta serie de televisión. El autor apunta como los referentes religiosos se paganizan en favor del uso de recursos fílmicos.

Philippe Merlo Morat se apoya en su capítulo en autores como Gilbert Durand, Vladimir Propp y Julien Greimas para responder dos preguntas que plantea al principio de su texto: ¿en qué consisten el mito y la mitología en la obra de Manuel Gutiérrez Aragón? Y ¿đe qué mitos se nutren su obra? Para Merlo Morat los mitemas utilizados por el director cántabro van desde lo bíblico a las mitologías clásicas aplicándolo a su forma de contar, pero no como una manera de transmisión de la mitología.

En el siguiente capítulo, de Fernando Ramos Arenas, indaga en dos conceptos enunciados por el director a la hora de plantear el relato: expresión y comunicabilidad. Para ello se sirve de la utilización de los mitos en esta filmografía. Este capítulo 
también profundiza en las diferencias entre el cine de las décadas setenta y ochenta con la ruptura en la mostración del mito de los noventa. Por su lado, José Luis Sánchez Noriega introduce el concepto de la comensalidad en su texto. Un cine que revela la importancia del mito y el rito y de la mano de estos dos elementos el sentarse a la mesa a comer realzado en el relato como una cuestión trascendente. El ritual de la comida, junto con el del bosque y el árbol sagrado, y el arquetipo de la madre, es, según apunta Sánchez Noriega: uno de los tres elementos más relevantes en la filmografía de Gutiérrez Aragón.

Posiblemente el capítulo más personal sea el de Jean-Claude Seguin que plantea una cuestión: ¿puede un plano resumir una película entera? La película seleccionada es Maravillas (1981), de esta analiza siete planos. Los contextualiza dentro de la narrativa de la película, delinea la composición de estos y pone de manifiesto la relación que tiene con otros textos. El volumen se cierra con una completa bibliografía y filmografía de Manuel Gutiérrez Aragón, incluyendo su obra escrita y monografías de otros autores.

En definitiva, estamos ante un libro que viene tanto a reivindicar la obra del realizador cántabro a través de una reactualización a la hora de releer su filmografía. Pero también es un manifiesto sobre una forma de entender el arte cinematográfico ligado al tiempo de la realidad pero que en ningún momento se olvida de cierta función social. 